\title{
Determination of the Perception Level of Life Style Innovations in Type 2 Diabetes Mellitus
}

\section{Yasemin Korkut $^{1}$, İsmail Balcıglu ${ }^{1}$, Kevser Onbası ${ }^{2}$}

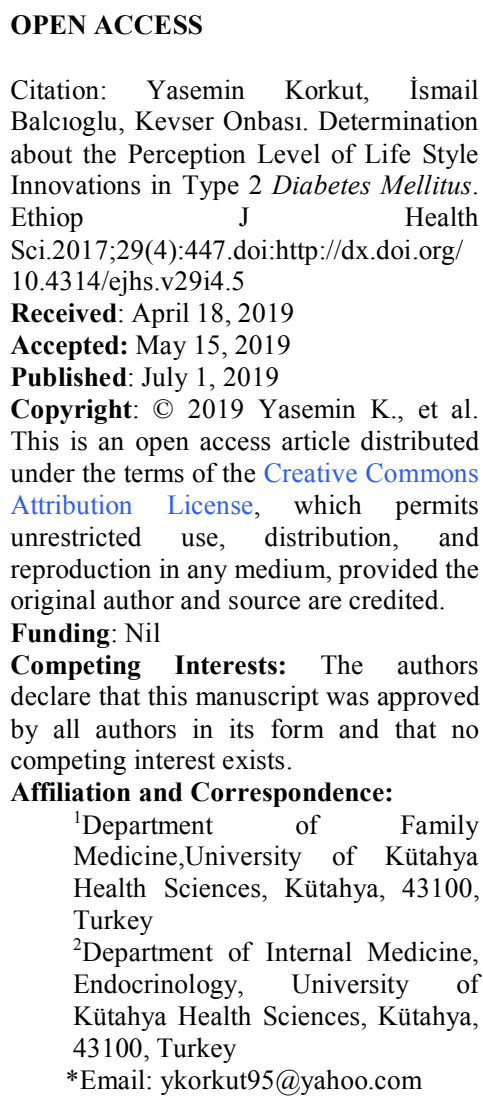

\section{ABSTRACT}

BACKGROUND: In this tudy, our aim was to measure information and behaviors of our patients about their diseases, and to determine the level of compliance with their treatment and to investigate the causes of nonconformities.

METHODS: A total of 111 patients who applied to outpatient clinics between May-December 2017 were included in this prospective cross-sectional study. Sociodemographic, clinical data, diabetes, medical nutrition therapy and physical activity questionnaires were administered face to face by the researchers.

RESULTS: About $68.5 \%$ of the 111 patients were females. While $64.9 \%$ were primary school graduates, $58.6 \%$ were housewives and 82.9\% were low income level. Body Mass Index (BMI) was found to be significantly higher in women $(p=0.041)$. It has been found that the awareness of the patients about themselves and their illnesses are $37.8 \%$ for $\mathrm{HbA1c}$, 64.8\% for fasting blood sugar level, 78.3\% for their height and body weight. While males had a higher score than females in the diabetes survey, females scored higher than males in the medical nutrition therapy and physical activity questionnaires. On the other hand, $46.8 \%$ of patients showed additional health problems as a cause of non-compliance to physical activity.

CONCLUSIONS: Level of knowledge and compliance with treatment were also found to be inadequate.

KEYWORDS: Type 2 diabetes, perception, awareness, diseases

\section{INTRODUCTION}

Along with the rapid change in lifestyle throughout the world, the prevalence of type 2 diabetes mellitus (T2DM) has also increased rapidly and become one of the leading health problems. T2DM is a genetic disease that develops with insulin resistance and deterioration in insulin secretion, often progressing insidiously, usually over 30 years of age (1). It has been shown that T2DM shortens the life span of 5-10 years, deteriorates the quality of life and increases the risk of cardiovascular disease 2-4 times. Diabetic patients have a two-fold higher risk of death from all causes than their healthy counterparts (2). 
According to the TURDEP-I study conducted in Turkey, the prevalence of T2DM was $7.2 \%$, while the rate of TURDEP-II increased to $13.7 \%$. The prevalence of T2DM is increasing in the early age period due to changes in diet and lifestyle. T2DM accounts for more than $90 \%$ of all diabetes patients and is the most common type of diabetes. Diabetes is ranked as the 8th commonest diseases among all causes of death worldwide (3). Most T2DM patients are obese or overweight (4). Treatment of the disease, diet, physical activity, patient education, oral antidiabetic agents, and insulin therapy may be mentioned in 5 main categories. Diet and physical activity are indispensable parts of the treatment plan in all types of diabetes. In patients with T2DM with diet, a decrease of $1-2 \%$ in $\mathrm{HbA} 1 \mathrm{c}$ levels can be achieved. Regular physical activity also provides a similar reduction. Invariant elements of treatment in all types of diabetes are patient education, medical nutrition therapy, and exercise (3). The American Dietetic Association and ADA recommend the delivery of diabetes patients to the dietitian within 1 month after diagnosis. On the other hand, 3-4 dietician interviews lasting 45-90 minutes in six months after T2DM diagnosis is recommended (4). It should be ensured that adult diabetics exercise at a medium intensity with a minimum of 150 minutes per week, at least 3 days per week on alternate days (4). The reasons of the increase in the prevalence of disease in recent years, population aging, unhealthy nutrition, obesity and sedentary life can be counted (5).

Treatment of T2DM involves significant lifestyle changes such as diabetic diet and regular physical activity. Planning adequate treatment including awareness of patients and education to reach a correct level of knowledge are directly related to the patient's perception. Thus, we would like to determine the consciousness level of T2DM patients about diet and physical activity by determining the causes of incompatibility to diet and physical activity.

\section{MATERIAL AND METHODS}

Place and time of research: This study was conducted between May 2017 to December 2017 in our hospital, Family Medicine and Endocrinology Outpatient clinics.
Research universe and sample: The universe of the research were the patients who were diagnosed with T2DM at least 1 year ago were admitted to our hospital with different reasons.

Sample of the research: Patients over the age of 30 , willing to participate in the study and literate were able to understand and answer the questions were selected patients.

Sample size: Sample volume of $95 \%$ confidence interval, $5 \%$ error margin was calculated as $\mathrm{p}=0.50$ to 384 in non-prevalence cases. After an additional 3 months, the study was terminated with 111 patients.

Exclusion criteria: Patients diagnosed with T2DM in the last one year, under the age of 30, impaired oral intake, disorientation discooperation, uncontrolled cardiac disease and with physical disabilities that would impede physical activity were excluded from the study.

Ethics committee approval: Approval for the study was taken from the Ethics Committee of Dumlupinar University Faculty of Medicine. The ethical clearance number is 2017-5/12.

Data collection tools: Sociodemographic data form, Clinical data form, Diabetes form, Medical Nutrition Therapy and Physical Activity questionnaire were used by the researcher. Patient declaration and/or hospital records were based on T2DM diagnosis. Informed consent form was obtained from patients.

Sociodemographic characteristics survey: We collected information about participants' age, gender, education, occupation, marital status, number of children, living area and income rate.

Clinical data survey: The patient's history and the family history of the disease, follow-up frequency, physical characteristics consist of 10 questions.

Diabetes questionnaire: In order to measure the level of awareness about diabetes, the questionnaire, which was designed with questions about the definition, diagnosis, treatment and complications of diabetes, was scored as 100 points. It consists of 15 questions.

Medical nutrition therapy questionnaire: It consists of 15 questions that measure attitudes, behaviors and knowledge of the patients. 
Physical activity survey: It consists of 9 questions that measure the physical activity levels of the patients, their knowledge about exercise and their attitudes.

Statistical analysis: All normally distributed variables were expressed as mean and SD. Normality tests were used to analyze the normal distribution of the variables. Parametric tests were used for the variables with normal distribution. T-test was used for the independent samples for the comparison of mean values of the two groups. Paired sample t-test was used for the variables with a group number 3 or higher. Data were summarized as mean \pm standard deviation.

Table 1: Sociodemographic characteristics
$P$-value $<0.05$ was considered statistically significant.

\section{RESULTS}

A total of 111 patients were included in the study. The majority of the patients were below the age of 65 years $(63.1 \%) ; 76$ patients $(68.5 \%)$ were females and $35(31.5 \%)$ were males. In educational status, 18 were illiterate, 5 were literate, 5 were primary, 72 were high school, 5 were university graduates; $65(58.6 \%)$ of the participants were housewives. Sociodemographic characteristics are given in Table 1.

\begin{tabular}{llll}
\hline Sociodemographic Characteristics & & \\
\hline Variable & Subgroups & Number(n=111) & Percent(\%) \\
\hline Gender & Male & 35 & 31,5 \\
Age & Female & 76 & 68,5 \\
Education Status & Under 65 years & 70 & 63,1 \\
& 65 years and older & 38 & 34,2 \\
& Illiterate & 18 & 16,2 \\
& Literate & 5 & 4,5 \\
Job & Primary education & 72 & 64,9 \\
& High school & 9 & 8,1 \\
& University & 5 & 4,5 \\
Income rate & Housewife & 65 & 58,6 \\
& Retired & 13 & 11,7 \\
& Worker & 9 & 8,1 \\
Miving Area & Officer & 8 & 7,2 \\
& Farmer & 5 & 4,5 \\
Marital status & Artisan & 1 & 0,9 \\
Social life & Low $(<2000)$ & 92 & 82,9 \\
& Middle $(2000-4000)$ & 13 & 11,7 \\
& High $(>4000)$ & 4 & 3,6 \\
& Married & 99 & 89,2 \\
& Single & 12 & 10,8 \\
& Living with family & 107 & 96,4 \\
& Living Alone & 6 & 5,4 \\
& City & 97 & 87,4 \\
& Rural & 13 & 11,7 \\
\hline
\end{tabular}

According to the duration of diabetes, the number of years was $79(71.2 \%)$. Oral antidiabetics were among patients diagnosed with diabetes for more than five the first treatment modalities. The mean HbAlc level of

DOI: http://dx.doi.org/10.4314/ejhs.v29i4.5 
the patients was $8.02 \%$. It is above the target value. The difference by gender was not significant. According to education level, the group with the highest HbAlc level was primary school graduates, and the lowest group was university graduates.

The mean fasting blood glucose level was $168 \mathrm{mg} / \mathrm{dl}$ in males and $188 \mathrm{mg} / \mathrm{dl}$ in females. Although the fasting

Table 2: Clinical information.

\begin{tabular}{|c|c|c|c|}
\hline Variable & Subgroups & Number(n=111) & Percent $(\%)$ \\
\hline \multirow[t]{2}{*}{ Diabetes Duration } & Under 5 years & 28 & 25,2 \\
\hline & 5 years and above & 79 & 71,2 \\
\hline \multirow[t]{3}{*}{ Treatment Type } & OAD & 48 & 43,2 \\
\hline & Insulin & 27 & 24,3 \\
\hline & OAD ve Insulin & 33 & 29,7 \\
\hline Variable & Subgroups & Average Value & $P<0.05$ \\
\hline \multirow[t]{9}{*}{ HbAlc (\%) } & All & 8,02 & - \\
\hline & Male & 7,41 & $\mathrm{p}=0.052$ \\
\hline & Female & 8,40 & \\
\hline & Primary education & 8,47 & \\
\hline & High school & 7,2 & - \\
\hline & University & 7,08 & \\
\hline & Housewife & 8,8 & \\
\hline & Retired & 7,62 & - \\
\hline & Officer & 7,12 & \\
\hline \multirow[t]{2}{*}{$\mathrm{FBG}(\mathrm{mg} / \mathrm{dl})$} & Male & 168 & $\mathrm{p}>0.05$ \\
\hline & Female & 188 & \\
\hline \multirow[t]{2}{*}{ BMI } & Male & 28,1 & $\mathrm{p}=0.041$ \\
\hline & Female & 32,1 & \\
\hline
\end{tabular}

Table 3: Consciousness form

\begin{tabular}{llll}
\hline Variable & Subgroups & Number(n=111) & Percent $(\%)$ \\
\hline HbAlc $(\%)$ & All & 42 & 37,8 \\
& Male & 16 & 45,7 \\
FBG $(\mathrm{mg} / \mathrm{dl})$ & Female & 26 & 34,2 \\
& All & 72 & 64,8 \\
MMI & Fale & 23 & 65,7 \\
& Female & 49 & 64,4 \\
Variable & Male & 87 & 78,3 \\
Diabetes score & Female & 32 & 91,4 \\
& Subgroups & 55 & 72,3 \\
Diet score & Male & Average Value & $\mathbf{P}<\mathbf{0 . 0 5}$ \\
& Female & 47 & $\mathrm{p}=0.022$ \\
Exercise score & Male & 41 & $\mathrm{p}=0.43$ \\
\hline
\end{tabular}

blood glucose levels were higher in women, the difference was not significant. Body Mass Index (BMI) was significantly higher in women $(p=0.041)$. BMI awareness has been found higher in males with a rate of 91.4\% (Table 2). 
Female

FBG:Fasting Blood Glucose BMI:Body Mass Index

It has been asked as "Do you know the value of HbAlc and FBG" for measurement of the level of awareness of the disease. The majority of males answered 'yes'. When the form that measures the level of consciousness about T2DM, the average score of males was significantly higher than females, respectively; 47 and 41 out of 100 points $(p=0.022)$. When the level of exercise consciousness was examined there was not statistically significant difference between males and females (Table 3).

According to the survey examining the reasons for non-compliance with diet and exercise, $35 \%$ of the patients stated that they did not comply with their dietary recommendations. The most common dietary discrepancy is that patients cannot prevent themselves. The other causes of non-compliance with diabetic diet were as follows: 'Very difficult to follow diet recommendations', I do not have the strength and time to prepare the recommended diet', 'I don't need a diabetic diet', 'I forget the suggestions', 'My blood sugar is very low'.

Although $88.2 \%$ of the patients $(\mathrm{n}=98)$ agreed that exercise was an important part of the treatment of the disease, $28.8 \%$ of them were doing regular and recommended physical activity, $42.3 \%$ did not exercise at all. The commonest exercise type was walking (64.8\%). The most common physical activity as a reason for noncompliance, $46.8 \%$ of the patients have other health reasons that prevent exercise.

\section{DISCUSSION}

It is known that having adequate information and correct attitude about the diseases for T2DM patients plays an effective role in the management of diabetes (6). Proper nutrition increases the quality of life in diabetic patients (7). In our study, the diet score was 64 points for females and 62 points for males (100 full points). There was no difference in gender $(\mathrm{p}=0.43)$.

Many studies have shown that physical activity has prevented or delayed progression of impaired glucose tolerance. Lifestyle changes, such as weight loss, can significantly reduce the risk of diabetes $(8,9)$. However, in such patients, weight loss of below $<5 \%$ does not allow access to metabolic results at a targeted level. When weight loss is above $>5 \%$, good results have been obtained at laboratory levels such as $\mathrm{HbAlc}$, lipid, and arterial blood pressure. In order to be over $5 \%$ of weight loss, regular physical activity and regular physician control are essential in addition to energy constraints (10). In our study, the exercise score was 53 points for males (100 full points). Exercise score was low, but there was no difference in gender $(\mathrm{p}=0.551)$. The diet and exercise scores were below the targeted value. The low level of exercise perception of the patients suggests that there is no exercise habit in the community.

In the study of Franz et al., it was found that weight loss in overweight or obese people with T2DM was not effective in providing glycemic control alone. They argued that the first stage of treatment was provided when proper nutrition, restriction in energy intake, regular physical exercise and training were applied together (7). In our patients, correct nutrition, regular exercise and education perception are low. The reason is composed of many components.

Erdem et al. have observed that $25 \%$ of the patients fully applied medical nutrition therapy. In this study, we found almost the same ratio. In the same study, $48 \%$ of the patients did not exercise before the diagnosis of diabetes, and this rate fell to $15 \%$ after diagnosis (5). In our study, there was no significant decrease in the rate of those who did not exercise before and after the diagnosis. This shows that health professionals do not provide adequate training to patients.

Atmaca et al. found that about half of the patients with diabetes had inadequate or inaccurate knowledge about the disease (1). The findings of our study were consistent with the available literature. In addition, it was seen that males were significantly more conscious than females, and the reason was higher education levels of males. Thus, we concluded that the level of education makes it easier to reach the information needed for awareness of a healthy lifestyle.

Tavakolizadeh et al. have shown that diabetic patients have significantly reduced their blood sugar levels, and that their diet and exercise habits have changed positively (11). In our study, $72.9 \%$ of the patients with T2DM were educated about diabetes. Only $23.5 \%$ of the educated patients were doing what they had learned during the training.

In another study, the use of long-term diabetes, insulin and oral antidiabetic combination, obesity or overweight, poor diet and low physical activity compliance, and follow-up incompatibility were associated with poor glycemic control. About $68 \%$ of the patients were on a diet, and $78.4 \%$ were found to be incompatible with exercise. In spite of the importance of diet and exercise, inconsistency is high especially in females. There was no significant correlation between

DOI: http://dx.doi.org/10.4314/ejhs.v29i4.5 
education level and treatment compliance (12). This shows that there are factors other than education for patient behavior. In our study, the patient stated that females could not control herself as the cause of noncompliance with the diet. We think to reach correct attitudes for diet is hard for females compared with males. This situation may be related to differences in hormonal status between the two genders.

In a study that investigated the causes and factors facilitating the change of positive behavior in T2DM patients and their families, lack of family and health service support, low-income level, and recommendations were seen as obstacles to behavior change (13). In our study, socioeconomic factors, and low and inadequate family support were found to be effective in patient perception. However, the role of environmental factors is higher than these. This shows that there is a much longer distance to be covered in terms of education.

As a result, it was determined that compliance with diabetes awareness and lifestyle changes were below the desired levels. Compliance with lifestyle changes of patients with T2DM can be achieved by planning patient education in a quick and multidisciplinary way and the work of all health professionals within a team understanding.

\section{REFERENCES}

1. Atmaca HU, Akbaş F, Şak T, Şak DU, Acar Ş, Niyazoğlu M. Consciousness Level and Disease Awareness among Patients with Diabetese. Istanbul Med J. 2015;16(3):101-104.

2. Yılmaz MT, Karadeniz Ş, Sargın M, Büyükbeşe A, Şengül A. Chronic Complications in Longterm Type 1 and Type 2 Diabetic Patients with Comparable Duration of Diabetes and Poor Glycemic Control: Turkish Diabetes Chronic Complications Trial-TUDIC Results 1. In The World Congress on Controversies in Obesity, Diabetes and Hypertension (CODHy) 2006;26-29.

3. Tosun N, Satman İ, Erkoç Y et al. Türkiye Diyabet Önleme ve Kontrol Programı Eylem Planı (20112014). Ankara: Anll Matbaası. 2011;1-30.

4. Satman İ. İmamoğlu Ş. Yılmaz C. Akalın S. Salman S. Dinççağ N. Diabetes Mellitus ve komplikasyonlarının tanı, tedavi ve izlem kılavuzu. Türkiye Endokrinoloji ve Metabolizma Derneği Ankara, 8rd ed, Miki press, 2016;15,22,24,53.

5. Erdem S, Bayrak B, Uğur M, Orman M, Akar H. Adaptation to Lifestyle Changes in Patients with Type 2 Diabetes Mellitus Istanbul Bilım University Florence Nightingale Journal of Medicine. 2016;2:243-246.

6. Binh TQ, Phuong PT, Nhung BT. Knowledge and Associated Factors Towards Type 2 Diabetes Among a Rural Population in the Red River Delta Region, Vietnam. Rural Remote Health. 2015;15(3);3275.

7. Breen C, Ryan M, Gibney MJ, O’Shea D. Diabetes Related Nutrition Knowledge and Dietary Intake Among Adults with Type 2 Diabetes. Br J Nutr. 2015;114:439-447.

8. Rossen J, Yngve A, Hagströmer M, Brismar K, Ainsworth BE, Iskull $\mathrm{C}$ et al. Physical Activity Promotion in The Primary Care Setting in Pre- and Type 2 Diabetes - the Sophia Step Study, an RCT. BMC Public Health 2015;15:647.

9. Miller CK, Nagaraja HN, Weinhold KR, Early Weightloss Success Identifies Nonresponders After a Lifestyle Intervention in a Worksite Diabetes Prevention Trial. $J$ Acad Nutr Diet. 2015;115:1464-1471.

10. Franz MJ, Boucher JL, Rutten-Ramos S, Van Wormer JJ. Lifestyle Weight-loss Intervention Outcomes in Overweight and Obese Adults with Type 2 Diabetes: A Systematic Review and Metaanalysis of Randomized Clinical Trials. J Acad Nutr Diet. 2015;115:1447-1463.

11. Tavakolizadeh J, Moghadas M, Ashraf H, Effect of Self-regulation Training on Management of Type 2 Diabetes. Iran Red Crescent Med J. 2014;16(4):e13506.

12. Al-Rasheedi A. The Role of Educational Level in Glycemic Control among Patients with Type II Diabetes Mellitus. International Journal of Health Sciences, Qassim University. 2014;8(2):177-187.

13. Albarran Noemi B, Ballesteros MN, Morales GG, Ortega MI. Dietary Behavior and Type 2; Diabetes Care. Patient Education and Counselling. 2006;61:191-199. 